(W)

Cite as

Nano-Micro Lett.

(2020) 12:30

Received: 19 October 2019

Accepted: 14 December 2019

Published online: 21 January 2020

(C) The Author(s) 2020

\section{Surface-Engineered $\mathrm{Li}_{4} \mathrm{Ti}_{5} \mathrm{O}_{12}$ Nanostructures for High-Power Li-Ion Batteries}

\author{
Binitha Gangaja ${ }^{1}$, Shantikumar Nair ${ }^{1}$, Dhamodaran Santhanagopalan ${ }^{1} \bowtie$ \\ $\triangle$ Dhamodaran Santhanagopalan, dsgopalan20710@aims.amrita.edu \\ 1 Centre for Nanosciences and Molecular Medicine, Amrita Vishwa Vidyapeetham, AIMS (P.O.), \\ Kochi 682 041, India
}

\title{
HIGHLIGHTS
}

- Surface-engineered $\mathrm{Li}_{4} \mathrm{Ti}_{5} \mathrm{O}_{12}$ nanoparticles were synthesized by an off-stoichiometric solvothermal process.

- The electrode exhibited ultrafast charge-discharge (up to 1200C) performances in a half-cell configuration.

- A full cell consisting of the engineered $\mathrm{Li}_{4} \mathrm{Ti}_{5} \mathrm{O}_{12}$ anode and $\mathrm{LiMn}_{2} \mathrm{O}_{4}$ cathode exhibited an ultrahigh-rate capability (up to $200 C$ ), long cycling life (1000 cycles), and robust performances (at $-10,25$, and $55^{\circ} \mathrm{C}$ ).

\begin{abstract}
Materials with high-power chargedischarge capabilities are of interest to overcome the power limitations of conventional Li-ion batteries. In this study, a unique solvothermal synthesis of $\mathrm{Li}_{4} \mathrm{Ti}_{5} \mathrm{O}_{12}$ nanoparticles is proposed by using an off-stoichiometric precursor ratio. A Li-deficient off-stoichiometry leads to the coexistence of phaseseparated crystalline nanoparticles of $\mathrm{Li}_{4} \mathrm{Ti}_{5} \mathrm{O}_{12}$ and $\mathrm{TiO}_{2}$ exhibiting reasonable high-rate performances. However, after the solvothermal process, an extended aging of the hydrolyzed solution leads to the formation of $\mathrm{a}_{4} \mathrm{Ti}_{5} \mathrm{O}_{12}$ nanoplate-like structure with a self-assembled disordered surface layer without crystalline $\mathrm{TiO}_{2}$. The $\mathrm{Li}_{4} \mathrm{Ti}_{5} \mathrm{O}_{12}$ nanoplates with the disordered surface layer deliver ultrahighrate performances for both charging and discharging

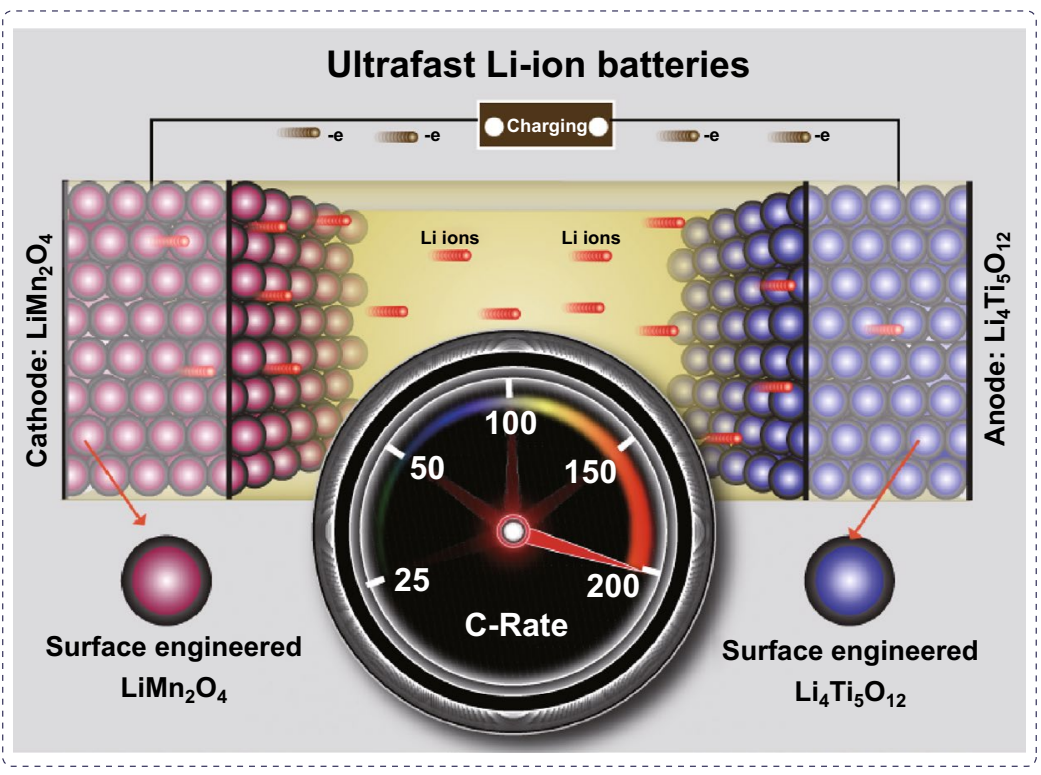
in the range of 50-300C and reversible capacities of 156 and $113 \mathrm{mAh} \mathrm{g}^{-1}$ at these two rates, respectively. Furthermore, the electrode exhibits an ultrahigh-charging-rate capability up to $1200 C$ (60 $\mathrm{mAh} \mathrm{g}^{-1}$; discharge limited to 100C). Unlike previously reported high-rate half cells, we demonstrate a high-power Li-ion battery by coupling $\mathrm{Li}_{4} \mathrm{Ti}_{5} \mathrm{O}_{12}$ with a high-rate $\mathrm{LiMn}_{2} \mathrm{O}_{4}$ cathode. The full cell exhibits ultrafast charging/discharging for 140 and $12 \mathrm{~s}$ while retaining 97 and $66 \%$ of the anode theoretical capacity, respectively. Room- $\left(25^{\circ} \mathrm{C}\right)$, low- $\left(-10{ }^{\circ} \mathrm{C}\right)$, and high- $\left(55^{\circ} \mathrm{C}\right)$ temperature cycling data show the wide temperature operation range of the cell at a high rate of $100 \mathrm{C}$.
\end{abstract}

KEYWORDS Ultrafast charging; Li-ion battery; Lithium titanate; Off-stoichiometric synthesis; Surface chemistry 


\section{Introduction}

Fast charging is one of the important aspects of modern energy storage devices, which can enable a smooth transition from gasoline to electric vehicles without reducing the safety. Owing to its high safety and zero strain property, lithium titanate $\left(\mathrm{Li}_{4} \mathrm{Ti}_{5} \mathrm{O}_{12}\right.$ (LTO)) has attracted significant interest as a negative-electrode material in lithium-ion batteries and capacitors [1, 2]. However, its transport properties (both ionic and electronic) are inherently limited and require significant changes for high-rate (higher than $60 \mathrm{C}$ ) applications $[3,4]$. The primary factors limiting the high-rate capability are the (1) lithium diffusion lengths in bulk particles, (2) poor percolated electronic conduction pathway across thick electrodes, and (3) electrode/electrolyte interface limiting the charge-transfer kinetics [5, 6]. To improve the rate capability of LTO, several strategies addressing at least one of the above three factors have been reported. For example, LTO particle size reduction to the nanoscale leads to better kinetics owing to the smaller diffusion lengths [6]. Feckl et al. [7] have reported nanoscale porous LTO thin films providing rate capabilities up to $800 C$. Nevertheless, the maximum electrode loading was only $0.14 \mathrm{mg} \mathrm{cm}^{-2}$, which limits their commercial application. Borghols et al. [8] have reported an ideal LTO particle size of approximately $30 \mathrm{~nm}$ to reversibly accommodate $\mathrm{Li}$ ions without considerable surface reconstruction. The electrical conductivity of a slurrycasted electrode can be improved by compositing largesurface-area and high-aspect-ratio carbon nanostructures as additives [9-12]. Carbon nanotubes (CNTs) as an additive can improve the rate capability of the electrode compared to the other forms of carbon [9-12]. However, it is believed that the crucial factor hindering the high-rate capabilities of electrode materials is the charge-transfer resistance at the electrode/electrolyte interface [13-17]. The electrode/ electrolyte interface enabling rapid charge-transfer kinetics is regulated by the surface chemistry of the nanoparticles in the electrode. Wang et al. [14] have synthesized rutile- $\mathrm{TiO}_{2}$ coated LTO nanosheets providing a significant improvement in specific capacity compared to that of the uncoated counterpart. The $\mathrm{TiO}_{2}$-coated LTO electrode reduced the chargetransfer resistance to half of that of the uncoated sample while maintaining the good Li diffusion kinetics owing to the epitaxial growth of rutile $\mathrm{TiO}_{2}$ along the [001] direction. Kang et al. [17] have demonstrated the potential of surface engineering on a cathode material by synthesizing an amorphous-lithium-phosphate-coated $\mathrm{LiFePO}_{4}$, which provided an ultrahigh-rate capability (397C) with a discharge capacity of almost $60 \mathrm{mAh} \mathrm{g}^{-1}$. The rapid ionic conduction through the amorphous surface has led to such high-rate performances. Most of the studies on fast charge-discharge have demonstrated the same strategy on half-cell configurations, which limits the real-time applications. In this study, we use off-stoichiometric (Li-deficient) originators and synthesize surface-engineered lithium titanate by inhibiting the phase separation and crystallization of $\mathrm{TiO}_{2}$. The flawless control of the surface chemistry of LTO enables a high-power Li-ion battery with charging/discharging as fast as $12 \mathrm{~s}$ and $66 \%$ of the LTO's theoretical capacity. A high-rate operation is also demonstrated in a wide temperature range of -10 to $55^{\circ} \mathrm{C}$.

\section{Experimental Section}

\subsection{Synthesis}

For the synthesis of LTO, an off-stoichiometric (Li-deficient) proportion of lithium and titanium precursors was utilized. In a typical procedure, a molar ratio of lithium hydroxide to titanium iso-propoxide of 3.6:5 was used for the synthesis of LTO nanoparticles [18]. Initially, lithium hydroxide dissolved in distilled water was added to an ethylene glycol solvent maintained at $100{ }^{\circ} \mathrm{C}$ and was allowed to stir for $15 \mathrm{~min}$. A titanium precursor was then added dropwise and allowed to stir until the formation of a clear solution. Subsequently, an ammonia solution $(4.2 \mathrm{~mL})$ was added. The obtained mixture was transferred to an autoclave, which was then maintained at $180{ }^{\circ} \mathrm{C}$ for $36 \mathrm{~h}$ in an oven. Upon completion of the $36 \mathrm{~h}$ solvothermal process, the obtained sample was centrifuged, washed, and annealed at $500{ }^{\circ} \mathrm{C}$ for $6 \mathrm{~h}$. After the $36 \mathrm{~h}$ solvothermal process, the whole autoclave was kept inside the oven at room temperature for 6 or $24 \mathrm{~h}$ (referred to as aging, and hence the resultant product is named as aged LTO). Subsequently, the obtained sample was centrifuged, washed, and annealed at $500{ }^{\circ} \mathrm{C}$ for $6 \mathrm{~h}$. The synthesis was repeated few times to evaluate the fabrication consistency of the aged LTO sample. For comparison, a sample with a ratio of 3.5:5 was fabricated through the aging process, denoted as aged LTO-3.5. 


\subsection{Structural and Electrochemical Characterizations}

The crystal structures and phases of the synthesized LTObased nanostructures were identified by using X-ray diffraction (XRD; Rigaku Ultimate IV, Japan) and Raman spectroscopy (WITec Alpha 300R, Germany). Low-magnification and high-resolution imagings and selected-area electron diffraction (SAED) were carried out using transmission electron microscopy (TEM; TECHNAI, FEI, The Netherlands). X-ray photo-electron spectroscopy (XPS; Kratos, Axis Ultra, UK) measurements were taken to obtain surface information of the sample. The electrochemical performances of the synthesized nanostructures were evaluated by fabricating electrodes by slurry casting with an active material/CNT/ polyvinylidene fluoride ratio of 75:15:10 (except for the rate test up to $1200 C$ carried out with a ratio of 70:20:10 in comparison with the literature). The electrode loading was maintained in the range of $1 \pm 0.2 \mathrm{mg} \mathrm{cm}^{-2}$. The cells were fabricated inside an Ar-filled glove box $\left(\mathrm{O}_{2}\right.$ and $\mathrm{H}_{2} \mathrm{O}$ maintained below 1.0 part per million) either as coin cells (CR 2032) or Swagelok cells (diameter: 0.5 inch) with $\mathrm{Li}$ as the counter electrode in a half-cell assembly and electrolyte of $1 \mathrm{M}$ of $\mathrm{LiPF}_{6}$ in ethylene carbonate/dimethyl carbonate. The half-cell electrochemical analysis was carried out in a voltage window of $0.8-3 \mathrm{~V}$ using an eight-channel battery cycler (BioLogic, USA). Li-ion battery full cells were fabricated by coupling the aged LTO sample with a $\mathrm{LiMn}_{2} \mathrm{O}_{4}$ (LMO) cathode in an anode-limited assembly cycled in a potential window of $1.5-3 \mathrm{~V}$.

\section{Results and Discussion}

The synthesis of the surface-engineered spinel LTO by the solvothermal process is illustrated in Fig. 1. Scheme 1 describes the Li-deficient (ratio of $\mathrm{Li} / \mathrm{Ti}$ of 3.6:5 against the nominal 4:5) process, which leads to LTO nanoparticles along with phase separation and crystallization of anatase $\mathrm{TiO}_{2}$. The XRD data are presented in the right panel of Fig. 1. The relative phase (weight) fractions of the components $\left(\mathrm{LTO}\right.$ and $\mathrm{TiO}_{2}$ ) in the sample were quantitatively calculated by using the XRD pattern and Klug's equation (Eq. 1):

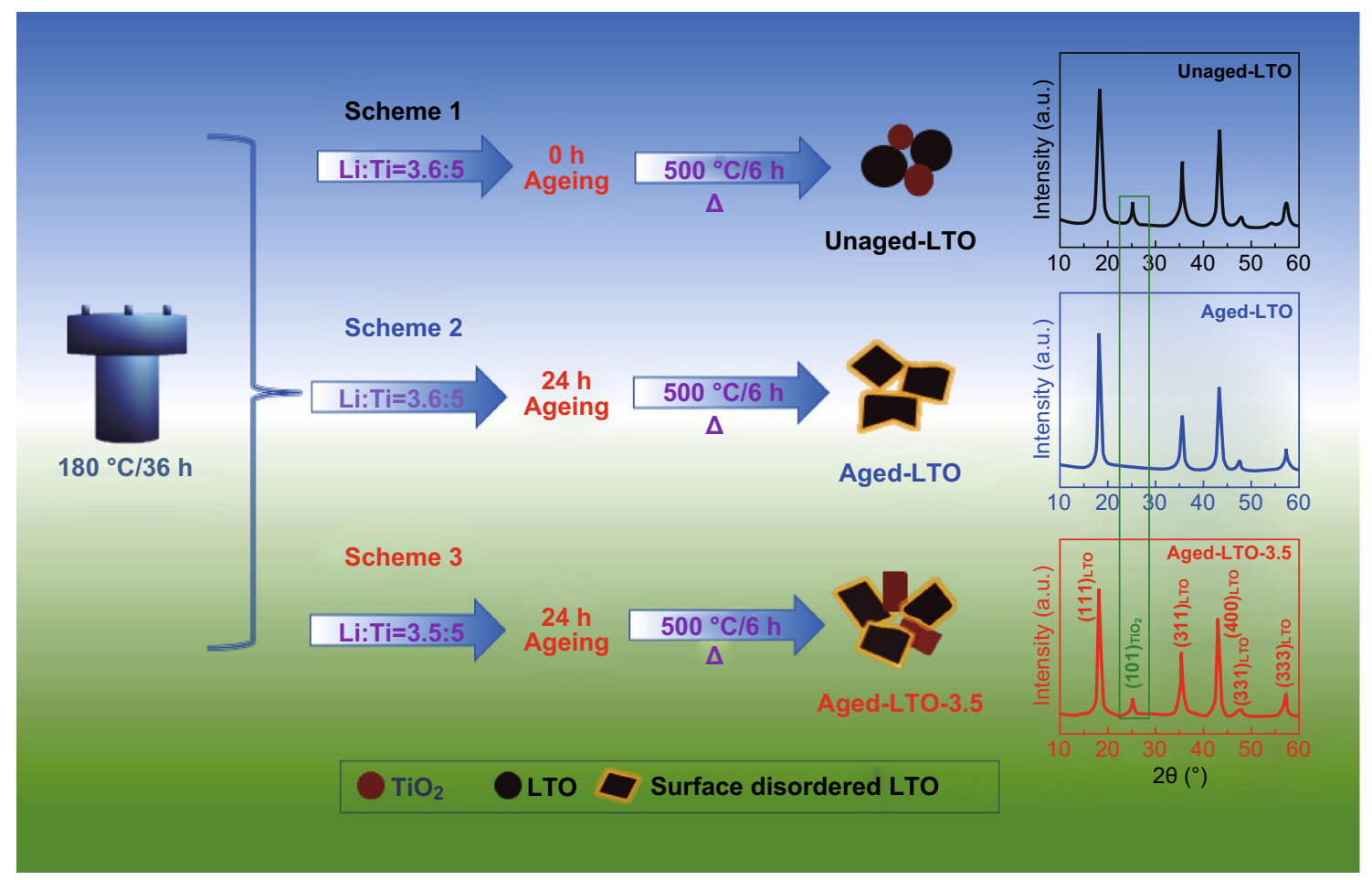

Fig. 1 Solvothermal Schemes 1-3 with the physical and chemical characteristics of the unaged LTO, aged LTO, and aged LTO-3.5 samples and their XRD patterns 
$W_{a}=I_{a} /\left(I_{a}+\frac{I_{b}}{K_{a}^{b}}\right)$

where $W_{a}$ is the weight fraction of component " $a$ " (LTO) in the mixed sample of LTO and $\mathrm{TiO}_{2}, I_{a}$ and $I_{b}$ are the integrated intensities of the highest peaks of components " $a$ " and " $b$," respectively, and $K_{a}^{b}$ (Eq. 2 ) is the ratio of the mass attenuation coefficients of components " $b$ " and " $a$ ":

$K_{a}^{b}=R_{b} / R_{a}$.

The mass attenuation coefficients of LTO $\left(R_{a}\right)$ and $\mathrm{TiO}_{2}$ $\left(R_{b}\right)$ are 103.94 and $118.65 \mathrm{~cm}^{2} / \mathrm{g}$, respectively. $I_{a}$ and $I_{b}$ of the unaged LTO sample were 444.54 and 79.96 , respectively. The weight fraction of component " $b$ " $\left(W_{b}\right.$, Eq. 3$)$ is

$W_{b}=1-W_{a}$.

Using these equations, the weight proportion of $\mathrm{LTO} / \mathrm{TiO}_{2}$ in the unaged LTO sample was calculated to be $84: 16$.

Scheme 2 describes the aging at the end of the $36 \mathrm{~h}$ solvothermal process, which inhibited the $\mathrm{TiO}_{2}$ phase separation and crystallization, as confirmed by the XRD pattern, showing the absence of $\mathrm{TiO}_{2}$. Scheme 3 illustrates the synthesis with a decreased $\mathrm{Li}$ concentration (or increased $\mathrm{Li}$ deficiency) and aging leading to a phase-separated and crystalized $\mathrm{TiO}_{2}$ along with LTO. The XRD analysis confirmed that the $\mathrm{TiO}_{2}$ weight fraction was approximately $7 \mathrm{wt} \%$ (against the expected $20 \mathrm{wt} \%$ ) [18]. This could be attributed to the aging enabling a certain weight fraction of $\mathrm{TiO}_{2}$ to selfassemble on the surface of LTO, while the remaining fraction was phase-separated and crystalized, which indicates that the surface layer thickness was possibly self-limited. The anatase $\mathrm{TiO}_{2}(101)$ peak at $24^{\circ}$ was observed in the XRD pattern (not observed for Scheme 2).

A Raman analysis was carried out to investigate the phases in the samples. Figure S1a shows the Raman spectra of the aged and unaged LTO samples. The unaged LTO sample exhibited peaks matching with both LTO and $\mathrm{TiO}_{2}$. However, the $E_{\mathrm{g}}$ peak was shifted to a larger wave number, which can be associated with two factors, (1) phonon confinement and (2) surface strain induced by the oxygen deficiency in the lattice $[19,20]$. The $\mathrm{TiO}_{2}$ signature was absent in the aged LTO, which confirms the absence of crystalline $\mathrm{TiO}_{2}$ particles in the sample. The $144 \mathrm{~cm}^{-1}\left(E_{\mathrm{g}}\right)$ vibration mode of $\mathrm{TiO}_{2}$ is very sensitive and is typically observed even for a small quantity of $\mathrm{TiO}_{2}$. The Raman analysis is consistent with the above XRD results, which confirms the presence and absence of $\mathrm{TiO}_{2}$ in the unaged and aged LTO samples, respectively. High-resolution Ti $2 p$ XP spectra of both samples are presented in Fig. S1c. Both samples exhibited similar profiles with a binding energy of $458.4 \mathrm{eV}$, which suggests the presence of octahedrally coordinated $\mathrm{Ti}$ species. The spin-orbit coupling of $5.7 \mathrm{eV}$ confirms the existence of $\mathrm{Ti}$ in the $4+$ oxidation state. As both $\mathrm{LTO}$ and $\mathrm{TiO}_{2}$ have $\mathrm{Ti}$ in the $4+$ oxidation state, it is challenging to independently identify their presence (as the XPS peaks overlay at the same binding energies). However, a small increase in peak width $(\sim 0.2 \mathrm{eV})$ was observed for the aged LTO sample, which could be originated from the formation of a disordered surface layer. Figure S1c shows a survey XP spectrum of the aged LTO sample, which confirms the absence of other surface impurities in the sample.
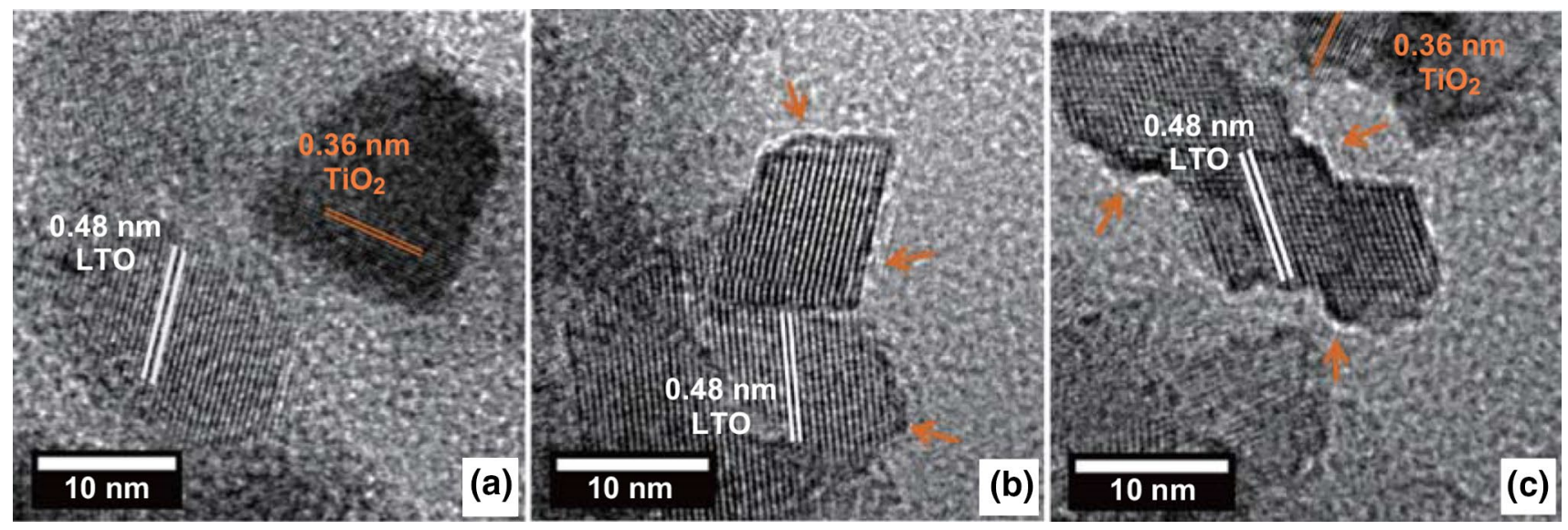

Fig. 2 High-resolution TEM analysis of the fabricated materials. a Unaged LTO with both $\mathrm{LTO}$ and $\mathrm{TiO}_{2}$ phases, $\mathbf{b}$ aged LTO with a disordered surface layer (indicated by arrows), and $\mathbf{c}$ aged LTO-3.5 with both disordered surface layer (indicated by arrows) and $\mathrm{TiO}_{2}$ phase 
The TEM results confirm the crystalline structures of all three samples, with average particle sizes of approximately $20 \mathrm{~nm}$ (Fig. 2a-c). This confirms that the aging did not lead to Ostwald ripening, but the particle size was preserved even after the aging. In addition, three striking features were observed in the TEM images. (1) The unaged sample contained both LTO and $\mathrm{TiO}_{2}$, (2) the aged LTO sample exhibited only an LTO plate-like morphology with a disordered surface layer, and (3) the aged LTO-3.5 contained a platelike LTO with a disordered surface layer as well as $\mathrm{TiO}_{2}$. These observations are consistent with the XRD results in Fig. 1. Notably, the unaged and aged samples exhibited similar morphologies before the annealing (Fig. S2a, b). However, after the annealing, the unaged sample exhibited a particle-like morphology, while the aged sample retained the plate-like morphology, as shown in the TEM images (Fig. 2a, b). Additional TEM images showing the surface disordered layer and plate-like morphology of the aged LTO sample are presented in Fig. S2c, d for reference. Figure S3 shows SAED patterns, which confirms the coexistence of crystalline $\mathrm{LTO}-\mathrm{TiO}_{2}$ phases in the unaged sample and only spinel LTO phase in the aged LTO sample, consistent with the XRD results. To correlate the morphology changes of the unaged and aged samples with the phase changes, XRD patterns were recorded before the annealing in comparison with those after the annealing. Before the annealing, all samples exhibited identical patterns (Fig. S4) with broad peaks, which could be indexed to the orthorhombic lithium titanate hydrate phase (JCPDS No. 00-047-0123). Upon the annealing, the unaged sample crystallized to $\mathrm{LTO}-\mathrm{TiO}_{2}$ (dual phase), while the aged sample crystallized to LTO (single phase). The formation of such a disordered surface layer could be explained as follows. Upon the completion of the solvothermal reaction, the lithium titanate hydrate phase formed in the Li-deficient precursor ratio. Annealing the solveothermal product immediately led to phase-separated crystalline $\mathrm{TiO}_{2}$ particles (dual phase) in the unaged LTO sample. However, before annealing, if these nanostructures are allowed to age, self-assembling could occur on the surface of LTO, which forms a disordered thin layer without crystallization of $\mathrm{TiO}_{2}$. For the aged LTO sample, this is confirmed by the absence of crystalline $\mathrm{TiO}_{2}$ according to
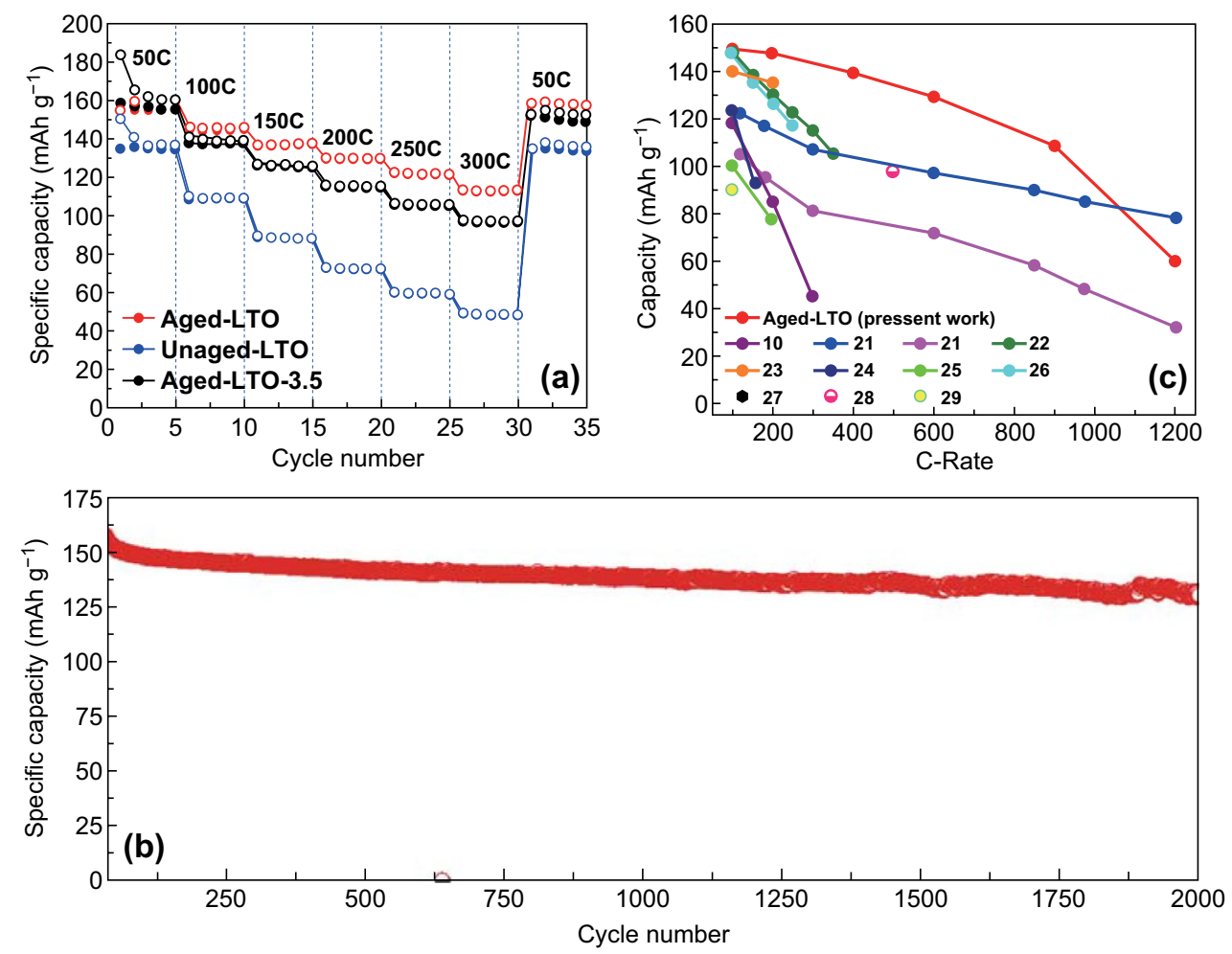

Fig. 3 Electrochemical performances of the half cells. a Ultrahigh-rate performances of the aged and unaged LTO electrodes at rates shown in the legend. b Long-cycling performance of the aged LTO sample at 50C. $\mathbf{c}$ Rate performance of the aged LTO sample up to $1200 \mathrm{C}$ and high-rate LTO literature values 
both XRD and TEM analyses. The aging requires approximately $24 \mathrm{~h}$. In this regard, another sample subjected to $6 \mathrm{~h}$ of aging was analyzed. It still exhibited the LTO-TiO dual phase (weight proportion of $\mathrm{LTO} / \mathrm{TiO}_{2}=88 / 12$ ) with a very small decrease in $\mathrm{TiO}_{2}$ fraction compared to that of the unaged sample (Fig. S5). This indicates that a larger aging time is required to inhibit the $\mathrm{TiO}_{2}$ phase separation and crystallization from the hydrated phase.

To evaluate the electrochemical performances of the surface-engineered nanostructures, we carried out a rate test (Fig. 3a) in the range of $50 \mathrm{C}$ to $300 \mathrm{C}$ (charge and discharge for five cycles at each rate). The aged LTO sample exhibited an exceptionally high performance with a value of $155.9 \mathrm{mAh} \mathrm{g}^{-1}$ at $50 \mathrm{C}$ and retained $72 \%$ of the initial capacity even at $300 C$ with a Coulombic efficiency of almost $100 \%$. According to the charge-discharge profiles in Fig. S6, the voltage plateau even at such ultrahigh rates indicates that the material underwent bulk lithiation/ delithiation rather than mere surface/interface storage. The charge-discharge voltage polarization of the aged LTO sample was smaller than that of the unaged LTO. The lower polarization indicates that the CNT additive formed a percolated conductive pathway with the smallest resistance for the electron transport across the thickness of the electrode. Even upon reversion from $300 C$ to $50 C$, the aged LTO electrode retained $100 \%$ of the value at the initial $50 \mathrm{C}$ cycles, which demonstrates the excellent reversibility and stability of the sample. The aged LTO-3.5 sample exhibited an inferior performance, though at $50 \mathrm{C}$ the performance was similar to that of the aged LTO; at $300 C$, the specific capacity was $156 \mathrm{mAh} \mathrm{g}^{-1}$. On the other hand, the unaged LTO sample exhibited a considerably lower performance, only $136 \mathrm{mAh} \mathrm{g}^{-1}$ at $50 \mathrm{C}$ and only 49 $\mathrm{mAh} \mathrm{g}^{-1}$ at $300 C$. The specific capacity of the aged LTO at $300 C$ was $134 \%$ higher than that of the unaged LTO sample. This difference is also reflected in the electrochemical impedance spectra (EIS) of cycled cells consisting of both samples, presented in Fig. S7. The lower charge-transfer resistance of the aged LTO can be related to the better transport of ions across the surface disordered layer. The diffusion coefficient of the aged LTO, calculated by using the EIS, was $0.75 \times 10^{-9} \mathrm{~cm}^{2} \mathrm{~s}^{-1}$, comparable or higher than those in the literature, mostly in the range of $10^{-9}$ to $10^{-13} \mathrm{~cm}^{2} \mathrm{~s}^{-1}[1,14]$. However, diffusion coefficients higher than those in this study have been reported [6]. The better diffusion coefficient could be attributed to the plate-like morphology promoting a better diffusion of $\mathrm{Li}$ ions. The electrochemical results demonstrate that ultrahigh-rate $(300 C)$ capabilities (both charge and discharge within $12 \mathrm{~s}$ ) can be achieved for a lithium-ion battery electrode while maintaining the high specific capacity.

Figure $3 \mathrm{~b}$ shows the long-cycling performances of the aged LTO samples cycled at a charge/discharge rate of $50 C$. The electrode delivered a first-cycle specific capacity of 156 $\mathrm{mAh} \mathrm{g}^{-1}$ and retained $82.6 \%$ of the initial capacity at the 2000th cycle. In addition, the electrode provided a charge capacity of $156 \mathrm{mAh} \mathrm{g}^{-1}$ and retention of approximately $70 \%$ at $100 C$ (discharge limited to 50C) for 2000 cycles (Fig. S8). Further, we investigated the ultrahigh-rate capability of the aged LTO through a rate test beyond $300 \mathrm{C}$. Figure $3 \mathrm{c}$ shows the rate performance of the aged LTO electrode (10 $0 C-200 C-400 C-600 C-900 C-1200 C$; all discharge rates were limited to $100 C$ ). The charge-discharge profiles are presented in Fig. S9. The electrode delivered specific capacities of $149 \mathrm{mAh} \mathrm{g}^{-1}$ at $100 C$ and $129 \mathrm{mAh} \mathrm{g}^{-1}$ at $600 C$. The obtained results are compared to ultrahigh-rate ( $100 \mathrm{C}$ or above) data reported in the literature in Fig. 3c [10, 21-29]. At the maximum charge rate of $1200 C$ (theoretically, equivalent to $100 \%$ delithiation in $3 \mathrm{~s}$ ), the electrode delivered almost $60 \mathrm{mAh} \mathrm{g}^{-1}$. The ultrahigh-rate supercapacitor-like battery performance of the aged LTO electrode confirms the potential of the surface engineering strategy for the fabrication of lithium-ion battery electrodes for high-power battery applications. We also compared the electrochemical performances of the aged LTO to those of other high-rate lithiumion battery electrode materials (Table S1) [17, 30-38].

The formation of the defective surface layer in the aged LTO enabled a faster charge transfer than those of the unaged LTO and even aged LTO 3.5. Moreover, in combination with the surface layer enabling the better charge transfer, the smaller particle size and nanoplate morphology led to a high diffusion coefficient. Additionally, the blending with the CNT additive provided a better electrode conductivity. Thus, by combining the principles of nanoengineering (synthesis of LTO nanoplates), surface engineering (formation of a defective surface layer), and electrode engineering (aged LTO composited with the high-aspect-ratio CNT additive), a battery with an ultrahigh-rate capacity, high cycling stability, and wide temperature range of operation was fabricated. In other words, the aged LTO sample addresses the above three aspects, which limit the rate performance of LTO, owing to the (1) synthesis of the nanoplate-like structure 
and improved diffusion kinetics, (2) electrode engineering by compositing with the CNT additive, and (3) surface engineering by creating a disordered surface layer, which facilitated the charge transfer at the electrode-electrolyte interface.

Considering the superior performance of the electrode, we also investigated its practical use by evaluating the effect of the active material loading through the delivered areal capacity. Figure $\mathrm{S} 10$ shows a high areal capacity of $0.6 \mathrm{mAh} \mathrm{cm}^{-2}$ at $10 C$ (loading: $3.56 \mathrm{mg} \mathrm{cm}^{-2}$ ) for 100 cycles. A detailed analysis is presented in Supplementary Material. Moreover, we investigated the structural stability of the aged LTO sample by ex situ TEM imaging on an electrode cycled at a rate of $10 C$ for 250 cycles. As shown in Fig. S11, the particles retained the surface-coated plate-like structure even after the long cycling, which demonstrates the structural stability.

To demonstrate the potential of the aged LTO for use in an ultrafast-charging battery, a full cell was fabricated by coupling the aged LTO with a spinel LMO cathode [39]. An anode-limited full cell was fabricated, and the cycling rates, specific capacity, and energy/power densities were calculated with respect to the active weight of the aged LTO [40]. Figure 4a shows the rate performance of the full cell in the voltage window of 1.5 to $3.0 \mathrm{~V}$. The full cell exhibited discharge capacities of 170, 157, 140, 127, and $115 \mathrm{mAh} \mathrm{g}^{-1}$ at ultrahigh rates of $25 C, 50 C, 100 C, 150 C$, and $200 C$, respectively, with respect to the LTO electrode. The ultrahigh-rate lithium-ion battery is beneficial for practical applications such as electric vehicles for fast charging and even for on-route charging. The first-cycle charge-discharge profiles of the full cell at different rates are shown in Fig. 4b. At 200C, the power and energy densities of the full cell were $76 \mathrm{~kW} \mathrm{~kg}^{-1}$ and $249 \mathrm{Wh} \mathrm{kg}^{-1}$, respectively (Table S2), which demonstrates the potential of the aged LTO-based full cell for high-power applications. Considering the theoretical specific capacity of the aged LTO, 65\% of the theoretical capacity was delivered in $12 \mathrm{~s}$ (at the rate of $200 C$ ). Figure $4 \mathrm{c}$ shows $\mathrm{d} Q \mathrm{~d} V^{-1}$ of the full cell at different rates, as indicated in the legend. Sharp peaks of the full cell were observed even at rates as high as $200 C$. The


Fig. 4 Electrochemical performances of the full cells. a Rate performance of the aged LTO/LMO full cell at high rates of $25 C$ to $200 C$. b Firstcycle charge-discharge profile of the fabricated aged LTO/LMO full cell. c d $Q \mathrm{~d} V^{-1}$ plots of the full cell at different rates (the inset shows the voltage polarization as a function of the $C$-rate). d Measured discharge voltages at different rates and different states of discharge corresponding to $25,50,75$, and $100 \mathrm{mAh} \mathrm{g}^{-1}$ 
inset shows the voltage polarization as a function of the $C$-rate, which shows a linear increase indicating a good rate capability. The voltage polarization was symmetric (at all rates) in the lithiation/delithiation, which indicates a fast intercalation/deintercalation of lithium. Figure $4 \mathrm{~d}$ shows the measured discharge voltages at different states of discharge corresponding to specific capacities of $25,50,75$, and 100 $\mathrm{mAh} \mathrm{g}^{-1}$. The smooth and linear voltage drop of the full cell confirms that the overvoltage was smaller than $0.5 \mathrm{~V}$ for the increase in $C$-rate from $25 C$ up to $200 C$. This was achieved by both electrode engineering at large scales and surface engineering at the nanoscale. These results show the excellent performances of the full cell at high charge-discharge rates reported in the literature so far.

In addition to the ultrahigh-rate capability, the full cell also exhibited a high cycling stability for 1000 cycles with a retention of approximately $82 \%$ at $50 C$ (after the rate test), as presented in Fig. 5a. As shown in the inset, four high-power light-emitting diodes could be lit with a single coin cell, which shows its power-delivering capability. Figure S12 presents results for the full cell consisting of the aged LTO-3.5 and LMO cathode, which exhibited a reasonably high-rate performance, though inferior to that of the aged LTO full cell. To evaluate the full-cell high-rate performances in a wide temperature range, the full cell (aged LTO and LMO) was tested at room temperature $\left(25^{\circ} \mathrm{C}\right)$, high temperature
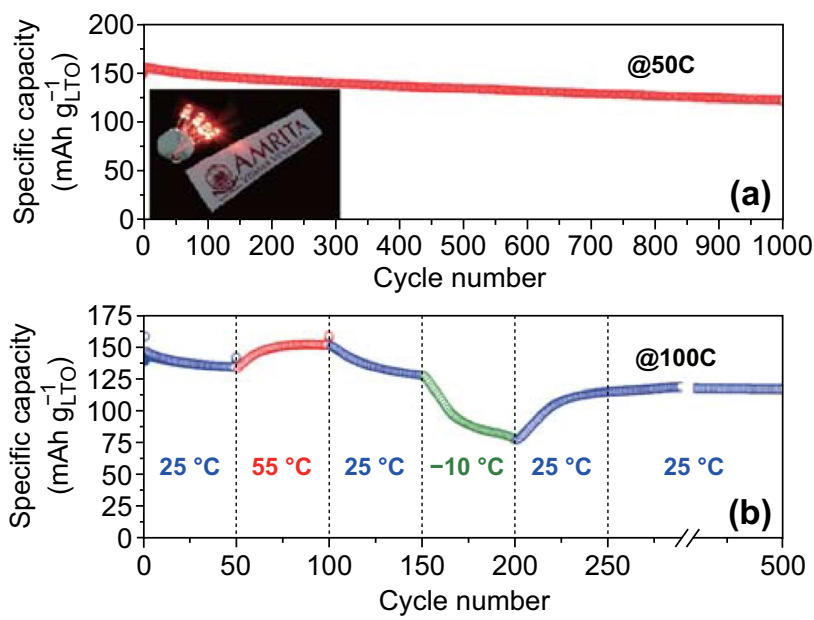

Fig. 5 Electrochemical cycling stability and operation temperature of the full cell. a Long-cycling performance at $50 \mathrm{C}$ (both charge and discharge). b Performances at different temperatures (shown in the legend) for cycling at $100 \mathrm{C}$. The inset in (a) shows that the four lightemitting diodes could be lit by the coin cell, which demonstrates the high-power capability $\left(55^{\circ} \mathrm{C}\right)$, and low temperature $\left(-10^{\circ} \mathrm{C}\right)$. Figure $5 \mathrm{~b}$ shows the specific capacity as a function of the cycle number for the full cell operated at various temperatures for 50 cycles (at each temperature, as indicated in the legend) at $100 \mathrm{C}$. The data show that the full cell retained almost $150 \mathrm{mAh}$ $\mathrm{g}^{-1}$ at the high temperature and above $75 \mathrm{mAh} \mathrm{g}^{-1}$ at the low temperature. After the thermal cycles and reversal to room temperature, the full cell was stable over 500 cycles and retained a capacity of $116 \mathrm{mAh} \mathrm{g}^{-1}$. Although LTO/ LMO full cells have been investigated by different groups, we report improved results in terms of rate capability and corresponding specific capacities [41-44]. The proposed structure is one of the safest electrode combinations with potentials for use in high-end electric vehicle applications $[45,46]$.

\section{Conclusions}

Surface-engineered LTO nanostructures fabricated through the off-stoichiometric (Li-deficient) solvothermal process and following aging exhibited an ultrahigh-rate capability. The aging had significant effects; it not only inhibited the $\mathrm{TiO}_{2}$ phase separation and crystallization, but also provided a self-assembled disordered surface layer on LTO. The further increase in Li deficiency led to the phase separation of $\mathrm{TiO}_{2}$ apart from the formation of the surface disordered layer, which indicates that its thickness was self-limited. The aged LTO plates as an anode for the Li-ion battery provided excellent electrochemical performances in terms of specific capacity, cycling life, and ultrahigh-rate capability. The electrode exhibited high specific capacities of $129 \mathrm{mAh} \mathrm{g}^{-1}$ at the high rate of $600 C$ and $60 \mathrm{mAh} \mathrm{g}^{-1}$ at $1200 C$. Further, the aged LTO/LMO full cell exhibited a fast charging-discharging (up to $200 \mathrm{C}$ with a time equivalent of $12 \mathrm{~s}$ ) and longcycling capability without affected capacity and nominal voltage. The high diffusion coefficient enabled the improved kinetics, the CNTs enabled the good electrode conductivity, and the surface disorder layer enabled the better charge transfer, which led to the ultrahigh-rate performance and cycling stability in the wide temperature range. This demonstrates that the control of the surfaces of the nanomaterials could enable high-power Li-ion batteries. This is a commercially viable strategy and can even be extended to other electrode materials to materialize the ultrahigh-power lithium-ion battery chemistries. 
Acknowledgements DS acknowledges Science and Engineering Research Board, India, for the Ramanujan Fellowship (Ref: SB/ S2/RJN-100/2014) and Department of Science and Technology, India, for the financial support (Ref: DST/TMD/MES/2k17/11). BG acknowledges Amrita Vishwa Vidyapeetham for the fellowship. We thank Prof. Shirley Meng (UC San Diego) for fruitful discussions and suggestions.

Open Access This article is licensed under a Creative Commons Attribution 4.0 International License, which permits use, sharing, adaptation, distribution and reproduction in any medium or format, as long as you give appropriate credit to the original author(s) and the source, provide a link to the Creative Commons licence, and indicate if changes were made. The images or other third party material in this article are included in the article's Creative Commons licence, unless indicated otherwise in a credit line to the material. If material is not included in the article's Creative Commons licence and your intended use is not permitted by statutory regulation or exceeds the permitted use, you will need to obtain permission directly from the copyright holder. To view a copy of this licence, visit http://creativecommons.org/licenses/by/4.0/.

Electronic supplementary material The online version of this article (https://doi.org/10.1007/s40820-020-0366-x) contains supplementary material, which is available to authorized users.

\section{References}

1. Y. Tao, Z. Tan, C. Ma, J. Yang, Z. Ma, S. Zheng, Challenges of spinel Li4Ti5O12 for lithium-ion battery industrial applications. Adv. Ener. Mater. 12, 1601625 (2017). https://doi. org/10.1002/aenm.201601625

2. Z. Yang, D. Choi, S. Kerisit, K.M. Rosso, D. Wang, J. Zhang, G. Graff, J. Liu, Nanostructures and lithium electrochemical reactivity of lithium titanites and titanium oxides: a review. J. Power Sources 192, 588-598 (2009). https://doi.org/10.1016/j. jpowsour.2009.02.038

3. J.C. Daigle, Y. Asakawa, M. Beaupre, V. Garipy, R. Vieillette, D. Laul, M. Trdeau, K. Zaghib, Boosting ultra-fast charge battery performance: filling porous nano $\mathrm{Li}_{4} \mathrm{Ti}_{5} \mathrm{O}_{12}$ particles with 3D network of N-doped carbons. Sci. Rep. 9, 16871 (2019). https://doi.org/10.1038/s41598-019-53195-1

4. Z. Yao, X. Xia, D. Xie, Y. Wang, S. Liu, S. Deng, X. Wang, $\mathrm{J}$. Tu, Enhancing ultrafast lithium ion storage of $\mathrm{Li}_{4} \mathrm{Ti}_{5} \mathrm{O}_{12}$ by tailored TiC/C core/shell skeleton plus nitrogen doping. Adv. Funct. Mater. 28, 1802756 (2018). https://doi.org/10.1002/ adfm.201802756

5. Y. Tang, Y. Zhang, W. Li, B. Ma, X. Chen, Rational material design for ultrafast rechargeable lithium-ion batteries. Chem. Soc. Rev. 44, 5926-5940 (2015). https://doi.org/10.1039/ C4CS00442F

6. L. Kavan, J. Procházka, T.M. Spitler, M. Kalbáč, M. Zukalová, T. Drezen, M. Grätzel, Li insertion into $\mathrm{Li}_{4} \mathrm{Ti}_{5} \mathrm{O}_{12}$ (Spinel).
J. Electrochem. Soc. 150, A1000-A1007 (2003). https://doi. org/10.1149/1.1581262

7. J.M. Feckl, K. Fominykh, M. Döblinger, D. Fattakhova-Rohlfing, T. Bein, Nanoscale porous framework of lithium titanate for ultrafast lithium insertion. Angew. Chem. Int. Ed. 51, 7459-7463 (2012). https://doi.org/10.1002/anie.201201463

8. W.J.H. Borghols, M. Wagemaker, U. Lafont, E.M. Kelder, F.M. Mulder, Size effects in the $\mathrm{Li}_{4+\mathrm{x}} \mathrm{Ti}_{5} \mathrm{O}_{12}$ spinel. J. Am. Chem. Soc. 131, 17786-17792 (2009). https://doi.org/10.1021/ja902 $423 \mathrm{e}$

9. B. Gangaja, K.S. Reddy, S. Nair, D. Santhanagopalan, Impact of carbon nanostructures as additives with spinel $\mathrm{Li}_{4} \mathrm{Ti}_{5} \mathrm{O}_{12} / \mathrm{LiMn}_{2} \mathrm{O}_{4}$ electrodes for lithium ion battery technology. ChemistrySelect 2, 9772-9776 (2017). https://doi. org/10.1002/slct.201702367

10. J.H. Jeong, M.S. Kim, Y.J. Choi, G.W. Lee, B.H. Park, S.W. Lee, K.C. Roh, K.B. Kim, Rational design of oxide/carbon composites to achieve superior rate-capability: via enhanced lithium-ion transport across carbon to oxide. J. Mater. Chem. A 6, 6033-6044 (2018). https://doi.org/10.1039/C8TA0 0883C

11. Z. Yao, X. Xia, C. Zhou, Y. Zhong, Y. Wang et al., Smart construction of integrated $\mathrm{CNTs} / \mathrm{Li}_{4} \mathrm{Ti}_{5} \mathrm{O}_{12}$ core/shell arrays with superior high-rate performance for application in lithium-ion batteries. Adv. Sci. 5, 1700786 (2018). https://doi. org/10.1002/advs.201700786

12. Y.R. Jhan, J.G. Duh, Synthesis of entanglement structure in nanosized $\mathrm{Li}_{4} \mathrm{Ti}_{5} \mathrm{O}_{12} /$ multi-walled carbon nanotubes composite anode material for Li-ion batteries by ball-milling-assisted solid-state reaction. J. Power Sources 198, 294-297 (2012). https://doi.org/10.1016/j.jpowsour.2011.09.063

13. H. Gu, F. Chen, C. Liu, J. Qian, M. Ni, T. Liu, Scalable fabrication of core shell structures $\mathrm{Li}_{4} \mathrm{Ti}_{5} \mathrm{O}_{12} / \mathrm{PPy}$ particles embedded in $\mathrm{N}$-doped graphene networks as advanced anode for lithium-ion batteries. J. Power Sources 369, 42-49 (2017). https://doi.org/10.1016/j.jpowsour.2017.09.083

14. Y.Q. Wang, L. Gu, Y.G. Guo, H. Li, X.Q. He, S. Tsukimoto, Y. Ikuhara, L.J. Wan, Rutile- $\mathrm{TiO}_{2}$ nanocoating for a high-rate $\mathrm{Li}_{4} \mathrm{Ti}_{5} \mathrm{O}_{12}$ anode of a lithium-ion battery. J. Am. Chem. Soc. 134, 7874-7879 (2012). https://doi.org/10.1021/ja301266w

15. B. Gangaja, P.H.P. Muralidharan, S. Nair, D. Santhanagopalan, Ultralong $(10 \mathrm{~K})$ cycle-life and high-power li-ion storage in $\mathrm{Li}_{4} \mathrm{Ti}_{5} \mathrm{O}_{12}$ films developed via sustainable electrophoretic deposition process. ACS Sustainable Chem. Eng. 6, 4705-4710 (2018). https://doi.org/10.1021/acssuschemeng.7b03787

16. H. Ni, L.Z. Fan, Nano- $\mathrm{Li}_{4} \mathrm{Ti}_{5} \mathrm{O}_{12}$ anchored on carbon nanotubes by liquid phase deposition as anode material for high rate lithium-ion batteries. J. Power Sources 214, 195-199 (2012). https://doi.org/10.1016/j.jpowsour.2012.04.074

17. B. Kang, G. Ceder, Battery materials for ultrafast charging and discharging. Nature 458, 190-193 (2009). https://doi. org/10.1038/nature07853

18. B. Gangaja, S.V. Nair, D. Santhanagopalan, Interface-engineered $\mathrm{Li}_{4} \mathrm{Ti}_{5} \mathrm{O}_{12}-\mathrm{TiO}_{2}$ dual-phase nanoparticles and CNT additive for supercapacitor-like high-power Li-ion battery 
applications. Nanotechnology 29, 095402 (2018). https://doi. org/10.1088/1361-6528/aaa2ea

19. C.Y. Xu, P.X. Zhang, L. Yan, Blue shift of Raman peak from coated $\mathrm{TiO}_{2}$ nanoparticles. J. Raman Spectrosc. 32, 862-865 (2001). https://doi.org/10.1002/jrs.773

20. B. Babu, S.G. Ullattil, R. Prasannachandran, J. Kavil, P. Periyat, M.M. Shaijumon, $\mathrm{Ti}^{3+}$ induced brown $\mathrm{TiO}_{2}$ nanotubes for high performance sodium-ion hybrid capacitors. ACS Sustainable Chem. Eng. 6, 5401-5412 (2018). https://doi. org/10.1021/acssuschemeng.8b00236

21. K. Naoi, W. Naoi, S. Aoyagi, J.-I. Miyamoto, T. Kamino, New generation "nanohybrid supercapacitor". Acc. Chem. Res. 46, 1075-1083 (2013). https://doi.org/10.1021/ar200308h

22. E. Zhao, C. Qin, H.R. Jung, G. Berdichevsky, A. Nese, S. Marder, G. Yushin, Lithium titanate confined in carbon nanopores for asymmetric supercapacitors. ACS Nano 10, 3977-3984 (2016). https://doi.org/10.1021/acsnano.6b00479

23. N. Li, Z. Chen, W. Ren, F. Li, H.-M. Cheng, Flexible graphenebased lithium ion batteries with ultrafast charge and discharge rates. Proc. Natl. Acad. Sci. U.S.A. 109, 17360-17365 (2012). https://doi.org/10.1073/pnas.1210072109

24. H.-G. Jung, S.-T. Myung, C.S. Yoon, S.-B. Son, K.H. Oh, K. Amine, B. Scrosati, Y.-K. Sun, Microscale spherical carboncoated $\mathrm{Li}_{4} \mathrm{Ti}_{5} \mathrm{O}_{12}$ as ultra high power anode material for lithium batteries. Energy Environ. Sci. 4, 1345-1351 (2011). https://doi. org/10.1039/c0ee00620c

25. S. Chen, Y. Xin, Y. Zhou, Y. Ma, H. Zhou, L. Qi, Self-supported $\mathrm{Li}_{4} \mathrm{Ti}_{5} \mathrm{O}_{12}$ nanosheet arrays for lithium ion batteries with excellent rate capability and ultralong cycle life. Energy Environ. Sci. 7, 1924-1930 (2014). https://doi.org/10.1039/c3ee42646g

26. L. Kavan, M. Grätzel, Facile synthesis of nanocrystalline $\mathrm{Li}_{4} \mathrm{Ti}_{5} \mathrm{O}_{12}$ (spinel) exhibiting fast $\mathrm{Li}$ insertion. Electrochem. Solid-State Lett. 5, A39-A42 (2002). https://doi. org/10.1149/1.1432783

27. J. Liu, X. Wei, X.W. Liu, Two-dimensional wavelike spinel lithium titanate for fast lithium storage. Sci. Rep. 5, 9782 (2015). https://doi.org/10.1038/srep09782

28. M. Odziomek, F. Chaput, A. Rutkowska, K. Świerczek, D. Olszewska, M. Sitarz, F. Lerouge, S. Parola, Hierarchically structured lithium titanate for ultrafast charging in long-life high capacity batteries. Nat. Commun. 8, 15636 (2017). https://doi. org/10.1038/ncomms 15636

29. J.H. Jeong, M.S. Kim, Y.H. Kim, K.C. Roh, K.B. Kim, Highrate $\mathrm{Li}_{4} \mathrm{Ti}_{5} \mathrm{O}_{12} / \mathrm{N}$-doped reduced graphene oxide composite using cyanamide both as nanospacer and a nitrogen doping source. J. Power Sources 336, 376-384 (2016). https://doi.org/10.1016/j. jpowsour.2016.11.015

30. S.T. Myung, M. Kikuchi, C.S. Yoon, H. Yashiro, S.J. Kim, Y.K. Sun, B. Scrosati, Black anatase titania enabling ultra high cycling rates for rechargeable lithium batteries. Energy Environ. Sci. 6, 2609-2614 (2013). https://doi.org/10.1039/c3ee41960f

31. H. Sun, L. Mei, J. Liang, Z. Zhao, C. Lee et al., Three-dimensional holey-graphene/niobia composite architectures for ultrahigh-rate energy storage. Science 356, 599-604 (2017). https:// doi.org/10.1126/science.aam5852
32. S. Lee, Y. Cho, H.K. Song, H.T. Lee, J. Cho, Carbon-coated single-crystal LiMn2O4 nanoparticle clusters as cathode material for high-energy and high-power lithium-ion batteries. Angew. Chem. Int. Ed. 51, 8748-8752 (2012). https://doi.org/10.1002/ anie. 201203581

33. F. Zoller, K. Peters, P.M. Zehetmaier, P. Zeller, M. Döblinger, T. Bein, Z. Sofer, D. Fattakhova-Rohlfing, Making ultrafast highcapacity anodes for lithium-ion batteries via antimony doping of nanosized tin oxide/graphene composites. Adv. Funct. Mater. 28, 1706529 (2018). https://doi.org/10.1002/adfm.201706529

34. H. Zhang, X. Yu, P.V. Braun, Three-dimensional bicontinuous ultrafast-charge and-discharge bulk battery electrodes. Nat. Nanotechnol. 6, 277-281 (2011). https://doi.org/10.1038/nnano .2011 .38

35. J. Hu, Y. Jiang, S. Cui, Y. Duan, T. Liu et al., 3D-printed cathodes of $\mathrm{LiMn}_{1-\mathrm{x}} \mathrm{Fe}_{\mathrm{x}} \mathrm{PO}_{4}$ nanocrystals achieve both ultrahigh rate and high capacity for advanced lithium-ion battery. Adv. Energy Mater. 6, 1600856 (2016). https://doi.org/10.1002/aenm.20160 0856

36. J. Zheng, Y. Hou, Y. Duan, X. Song, Y. Wei et al., Janus solidliquid interface enabling ultrahigh charging and discharging rate for advanced lithium-ion batteries. Nano Lett. 15, 6102-6109 (2015). https://doi.org/10.1021/acs.nanolett.5b02379

37. W. Guo, Y.X. Yin, S. Xin, Y.G. Guo, L.J. Wan, Superior radical polymer cathode material with a two-electron process redox reaction promoted by graphene. Energy Environ. Sci. 5, 52215225 (2012). https://doi.org/10.1039/C1EE02148F

38. Z.S. Wu, W. Ren, L. Xu, F. Li, H.M. Cheng, Doped graphene sheets as anode materials with superhigh rate and large capacity for lithium ion batteries. ACS Nano 5, 5463-5471 (2011). https ://doi.org/10.1021/nn2006249

39. S.R. Kasireddy, B. Gangaja, S.V. Nair, D. Santhanagopalan, $\mathrm{Mn}^{4+}$ rich surface enabled elevated temperature and full-cell cycling performance of $\mathrm{LiMn}_{2} \mathrm{O}_{4}$ cathode material. Electrochim. Acta 250, 359-367 (2017). https://doi.org/10.1016/j.elect acta.2017.08.054

40. G. Armstrong, A.R. Armstrong, P.G. Bruce, P. Reale, B. Scrosati, $\mathrm{TiO}_{2}(\mathrm{~B})$ nanowires as an improved anode material for lithium-ion batteries containing $\mathrm{LiFePO}_{4}$ or $\mathrm{LiNi}_{0.5} \mathrm{Mn}_{1.5} \mathrm{O}_{4}$ cathodes and a polymer electrolyte. Adv. Mater. 18, 2597 (2014). https://doi.org/10.1002/adma.200601232

41. Z. Weng, Z. Wang, W. Peng, H. Guo, X. Li, An improved solidstate reaction to synthesize $\mathrm{Zr}$-doped $\mathrm{Li}_{4} \mathrm{Ti}_{5} \mathrm{O}_{12}$ anode material and its application in $\mathrm{LiMn}_{2} \mathrm{O}_{4} / \mathrm{Li}_{4} \mathrm{Ti}_{5} \mathrm{O}_{12}$ full-cell. Ceram. Int. 40, 10053-10059 (2014). https://doi.org/10.1016/j.ceram int.2014.04.011

42. X. Wang, B. Liu, X. Hou, Q. Wang, W. Li, D. Chen, G. Shen, Ultralong-life and high-rate web-like $\mathrm{Li}_{4} \mathrm{Ti}_{5} \mathrm{O}_{12}$ anode for highperformance flexible lithium-ion batteries. Nano Res. 7, 10731082 (2014). https://doi.org/10.1007/s12274-014-0470-7

43. G. Xu, P. Han, S. Dong, H. Liu, G. Cui, L. Chen, $\mathrm{Li}_{4} \mathrm{Ti}_{5} \mathrm{O}_{12}$-based energy conversion and storage systems: status and prospects. Coord. Chem. Rev. 343, 139-184 (2017). https://doi. org/10.1016/j.ccr.2017.05.006

44. X. Su, J. Liu, C. Zhang, T. Huang, Y. Wang, A. Yu, High power lithium-ion battery based on $\mathrm{LiMn}_{2} \mathrm{O}_{4}$ nanorod cathode and a 
carbon-coated $\mathrm{Li}_{4} \mathrm{Ti}_{5} \mathrm{O}_{12}$ nanowire anode. RSC Adv. 6, 107355107363 (2016). https://doi.org/10.1039/C6RA23590E

45. I. Belharouak, Y.-K. Sun, W. Lu, K. Amine, On the safety of the $\mathrm{Li}_{4} \mathrm{Ti}_{5} \mathrm{O}_{12} / \mathrm{LiMn}_{2} \mathrm{O}_{4}$ lithium-ion battery system. J. Electrochem. Soc. 154, A1083-A1087 (2007). https://doi. org/10.1149/1.2783770
46. O.K. Park, Y. Cho, S. Lee, H.-C. Yoo, H.-K. Song, J. Cho, Who will drive electric vehicles, Olivine or Spinel? Energy Environ. Sci. 4, 1621-1633 (2011). https://doi.org/10.1039/c0ee00559b 